\title{
Neurological disease in wild loggerhead sea turtles Caretta caretta
}

\author{
Elliott R. Jacobson ${ }^{1, *}$, Bruce L. Homer ${ }^{1}$, Brian A. Stacy ${ }^{1}$, Ellis C. Greiner ${ }^{1}$, \\ Nancy J. Szabo ${ }^{1}$, Cheryl L. Chrisman ${ }^{1}$, Francesco Origgi ${ }^{1}$, Sadie Coberley ${ }^{2}$, \\ Allen M. Foley ${ }^{3}$, Jan H. Landsberg ${ }^{3}$, Leanne Flewelling ${ }^{3}$, Ruth Y. Ewing ${ }^{4}$, Richie \\ Moretti $^{5}$, Susan Schaf ${ }^{5}$, Corinne Rose ${ }^{5}$, Douglas R. Mader ${ }^{5}$, Glenn R. Harman ${ }^{6}$, \\ Charles A. Manire ${ }^{7}$, Nancy S. Mettee ${ }^{8}$, Andrew P. Mizisin ${ }^{9}$, G. Diane Shelton ${ }^{9}$ \\ ${ }^{1}$ College of Veterinary Medicine, University of Florida, Gainesville, Florida 32610, USA \\ ${ }^{2}$ College of Medicine, University of Florida, Gainesville, Florida 32610, USA \\ ${ }^{3}$ Florida Fish and Wildlife Conservation Commission, Fish and Wildlife Research Institute, St. Petersburg \\ Florida 33701, USA \\ ${ }^{4}$ National Marine Fisheries Service, Miami, Florida 33149, USA \\ ${ }^{5}$ Turtle Hospital, Marathon, Florida 33050, USA \\ ${ }^{6}$ Clearwater Marine Aquarium, 249 Windward Passage, Clearwater, Florida 33767, USA \\ ${ }^{7}$ Mote Marine Laboratory, Sarasota, Florida 34236, USA \\ ${ }^{8}$ Marinelife Center, Juno Beach, Florida, 33408, USA \\ ${ }^{9}$ Department of Pathology, School of Medicine, University of California, San Diego, La Jolla, California 92093-0612, USA
}

\begin{abstract}
Beginning in October 2000, subadult loggerhead sea turtles Caretta caretta showing clinical signs of a neurological disorder were found in waters off south Florida, USA. Histopathology indicated generalized and neurologic spirorchiidiasis. In loggerhead sea turtles (LST) with neurospirorchiidiasis, adult trematodes were found in the meninges of the brain and spinal cord of 7 and 3 affected turtles respectively, and multiple encephalic intravascular or perivascular eggs were associated with granulomatous or mixed leukocytic inflammation, vasculitis, edema, axonal degeneration and occasional necrosis. Adult spirorchiids were dissected from meningeal vessels of 2 of 11 LST brains and 1 of 10 spinal cords and were identified as Neospirorchis sp. Affected LST were evaluated for brevetoxins, ciguatoxins, saxitoxins, domoic acid and palytoxin. While tissues from 7 of 20 LST tested positive for brevetoxins, the levels were not considered to be in a range causing acute toxicosis. No known natural (algal blooms) or anthropogenic (pollutant spills) stressors co-occurred with the turtle mortality. While heavy metal toxicosis and organophosphate toxicosis were also investigated as possible causes, there was no evidence for their involvement. We speculate that the clinical signs and pathologic changes seen in the affected LST resulted from combined heavy spirorchiid parasitism and possible chronic exposure to a novel toxin present in the diet of LST.
\end{abstract}

KEY WORDS: Spirorchiidiasis $\cdot$ Brain $\cdot$ Spinal cord $\cdot$ Neuropathy $\cdot$ Loggerhead sea turtle Caretta caretta Resale or republication not permitted without written consent of the publisher

\section{INTRODUCTION}

While a wide variety of infectious and noninfectious diseases have been reported in wild and captive sea turtles (George 1997), little is known about the causes of neurologic disease in these animals. Despite pub- lished information on the performance of a neurologic examination in the green turtle (Chrisman et al. 1997), the assessment of the central and peripheral nervous system may not be routinely performed when sick sea turtles are brought into rehabilitation facilities for treatment. Thus, neurologic disease in sea turtles may 
be under-diagnosed rather than being a rare occurrence.

Digenetic trematodes of the family Spirorchiidae utilize freshwater turtles and sea turtles as their definitive hosts, and are known to cause neurologic complications. At least 8 genera and 20 species of spirorchiids infect the loggerhead Caretta caretta, green Chelonia mydas and hawksbill Eretmochelys imbricata sea turtles (Lauckner 1985), and are the most pathogenic of sea turtle parasites (George 1997). Spirorchiids are vascular system generalists, with a preference for the heart and arterial system of their turtle hosts (Platt \& Brooks 1997). Adult parasites may cause endocarditis, arteritis and thrombosis of the blood vessels (Gordon et al. 1998). In addition to direct pathological effects induced by the adult parasite, eggs released within the vascular system may be transported to remote areas, such as the central nervous system (CNS), where they lodge in small vessels, often initiating a mild to severe granulomatous inflammatory response. The eggs can also migrate through blood vessel walls, causing tissue damage and inflammation in adjacent tissues (Gordon et al. 1998). Spirorchiid parasitism may promote secondary gram-negative bacterial infections (Raidal et al. 1998). Meningitis and encephalitis have been reported in green turtles and LST in response to parasitism by intravascular spirorchiid trematode eggs (Gordon et al. 1998).

Approximately 40 marine and freshwater microalgal species are neurotoxic (Landsberg 2002), and about 16 occur in Florida's aquatic systems (Steidinger 1993). Globally, only a few of these microalgal toxins have been associated with acute marine animal mortalities (Landsberg 2002). Of the neurotoxic microalgae affecting sea turtles in Florida, only brevetoxins from the red-tide dinoflagellate Karenia brevis have previously been implicated in their mortalities (Gunter et al. 1948, L. Flewelling \& A. Foley unpubl.).

Here we report an epidemic of a neurological disease in loggerhead sea turtles in coastal waters of southern Florida, USA. Clinical, neurological, pathologic, parasitological and toxicological findings are presented.

\section{MATERIALS AND METHODS}

Stranding data. Dead or debilitated LST were documented in the field by participants in Florida's Sea Turtle Stranding and Salvage Network (FLSTSSN) from 5 October 2000 to 24 March 2001. Some of the LST were found floating and others were found washed ashore. The FLSTSSN observers typically noted the location of the turtle, species, curved or straight-line carapace length (from the nuchal notch to the posterior marginal tip), curved or straight-line carapace width (at the widest point), and anomalies associated with the turtle (e.g. tumors, boat-related injuries, shark bites, entanglement, emaciation). State and federal coordinators of the FLSTSSN reviewed all reports.

Clinical findings. From October 2000 to March 2001, 35 LST (6 males, the remainder being either female or unsexed immature LST) with similar clinical signs and in a debilitated condition were admitted to the Turtle Hospital, Marathon, Florida. Each turtle received a thorough physical examination, and whole body radiographs were taken. At the time of arrival, blood was collected from each turtle and submitted to a commercial clinical pathology laboratory (Antech Diagnostics) for complete blood counts and determination of plasma biochemicals. Since the LST were too weak to hold their heads out of water, and in order to prevent drowning, all LST were housed indoors in individual dry pools. The temperature was maintained at approximately $26^{\circ} \mathrm{C}$. The LST were force-fed and received oral fluids, and were administered a variety of drugs including antimicrobials, antihistamines, steroids and anthelminthics. Since organophosphate toxicosis was considered in the differential diagnosis, the last 6 LST arriving at the Turtle Hospital were treated with atropine (0.1 to $0.2 \mathrm{mg} \mathrm{kg}^{-1}$ intramuscular [IM]; Phoenix Scientific) and pralidoxichloride (Protopam Chloride, 1 g $49 \mathrm{~kg}^{-1}$ IM; Wyeth-Ayerst).

Upon arrival at the Turtle Hospital, the weight and straight carapace length (SCL) of affected LST were determined. The weights of the affected LST (33.8 to $109.6 \mathrm{~kg}$ ) were expressed as a function of their SCL $(64.7$ to $101 \mathrm{~cm})$, and a linear regression was derived. This was compared to a linear regression of the weight (22 to $114 \mathrm{~kg}$ ) and SCL (48.9 to $94.8 \mathrm{~cm}$ ) of 50 clinically healthy LST captured prior to October 2000 during a long-term in-water study of LST in south Florida. The slope and elevation of the 2 regression lines were compared using a Student's $t$-test (Zar 1984).

Neurological and electrophysiological examination. We evaluated 3 affected and 1 normal LST at the Veterinary Medical Teaching Hospital, University of Florida. Neurological examination included an evaluation of the integrity of the cranial and peripheral nerves (Chrisman et al. 1997). Electromyography and measurement of motor nerve conduction velocities were also performed as previously described for small animals (Chrisman 1991).

Pathology. Of the affected LST that died, 18 (ranging in weight from 33.8 to $125.5 \mathrm{~kg}$ and with an SCL of 64.7 to $97 \mathrm{~cm}$ ) were necropsied. During necropsy, organs were generally removed en bloc, and the brain was extracted from the skull. Following removal of the brain, the head was sectioned longitudinally along the mid-line for examination of the nasal cavity. The spinal 
cord was removed using a band saw and rotating necropsy saw. Of the 18 affected LST that were necropsied, a portion of the brain of 11 was examined for spirorchiid trematode eggs and adults using a stereoscope with an $8 \times$ to $40 \times$ viewing magnification. Spinal cords of 10 affected LST were similarly examined. The presence and relative densities of eggs and adult spirorchiids were noted. Eggs were removed, placed in wet mounts on glass slides, and examined using a light microscope. Efforts were made to remove adult parasites from blood vessels using fine insect-pin probes, jeweler's forceps and iridectomy scalpel blades.

Tissue sections from all major organ systems were fixed in $10 \%$ neutral-buffered formalin (NBF) for 24 to $48 \mathrm{~h}$, embedded in paraffin, sectioned at 5 to $6 \mu \mathrm{m}$, and stained with hematoxylin and eosin and as necessary, with a variety of stains for bacteria, fungi, myelin and collagen. The gastrointestinal contents of 18 LST were collected and examined for identification of food items.

Central nervous system (CNS) tissues from the 18 affected LST were compared with archived samples of the CNS of 14 LST (control group) that were necropsied from 1997 to 2001 and had died from other causes. While some of the control LST were from counties on the east and west coast of Florida that overlapped with the range of the affected group, others were from counties north of the area having affected LST. Using blind examination, each microscopic slide of the CNS from all LST was randomly given a unique number and graded individually for the presence of adult spirorchiid trematode eggs. The following criteria were used to grade trematode burdens: Grade 0, no trematodes; Grade 1, rare to small numbers of trematode eggs within brain/spinal cord parenchyma and/or meninges; Grade 2, moderate numbers of trematode eggs within brain/spinal cord parenchyma and/or meninges; Grade 3, large numbers and/or large clusters of trematode eggs within brain/spinal cord parenchyma and/or meninges. When there was a discrepancy in grades between slides from the same individual, the higher score was assigned. Brain and spinal cord grades, however, were assigned separately. In addition, it was noted if there were trematode adults present in examined sections. Of the collected cases, brain sections from 18 affected LST and 13 control turtles and spinal cord from 16 affected LST and four control turtles were available for examination.

Muscle histopathology and histochemistry. Fresh frozen-muscle specimens from various thoracic and pelvic limb muscles (76 specimens from 21 affected turtles) were evaluated. Frozen sections $(8 \mu \mathrm{m})$ were prepared and stained with hematoxylin and eosin, modified Gomori trichrome, periodic acid-Schiff and hematoxylin, and oil red $\mathrm{O}$, or incubated and stained for the histochemical localization of nicotinamide adenine dinucleiotide dehydrodgenase, myofibrillar adenosine triphosphatase, acid phosphatase, esterase and peroxidase according to standard methodologies (Dubowitz 1985). Muscle tissue fixed in NBF was also processed for light microscopy.

Peripheral nerve histopathology, morphometry and electron microscopy. Ulnar and sciatic nerve specimens from 21 affected LST were collected under anesthesia or at necropsy. Control specimens were obtained from 6 LST that had died of unrelated traumatic injuries. Nerve specimens were shipped in NBF, Trump's solution or $2.5 \%$ glutaraldehyde in phosphate buffer, and fixed muscle specimens in NBF. Subsequently, specimens for transmission electron microscopy were rinsed in phosphate buffer and postfixed in $1 \%$ phosphate-buffered osmium tetroxide for 3 to $4 \mathrm{~h}$ before dehydration, using a series of graded alcohols and propylene oxide. After infiltration with a 1:1 mixture of propylene oxide and araldite for $4 \mathrm{~h}$, nerves were placed in $100 \%$ araldite overnight before embedding in fresh araldite resin. Thick sections $(1 \mu \mathrm{m})$ were cut with glass knives and stained with toluidine blue prior to light microscope examination. Thin sections (60 to $90 \mathrm{~nm}$ ) from 3 affected turtles were stained with uranyl acetate and lead citrate before examination in a Zeiss 10 electron microscope operating at $80 \mathrm{keV}$.

Computer-assisted analyses of axonal sizefrequency distributions of myelinated fibers were performed on 7 sciatic nerves from affected turtles and 5 nerves from unaffected control turtles that were wellfixed and free from major artifact. For each nerve, a single thick section was analyzed as described previously (Mizisin et al. 1998). Briefly, a video image was obtained with an Olympus BH-2 light microscope and Cohu 5000-series television camera interfaced with a Macintosh Quadra 850AV computer running NIH Image 1.55 software. Myelinated fibers with axons greater than $1 \mu \mathrm{m}$ in diameter were individually identified and selected prior to sorting with an automated process into bins based on axonal diameter. Prior to and during analysis, video images of myelinated fibers were checked against the light microscope images in order to assess axonal integrity and ensure that only internodal profiles were sampled. Axons of myelinated fibers with profiles including the Schwann cell nucleus or paranode were not analyzed. In each case, the whole fascicle was systematically sampled with nonoverlapping fields, resulting in samples from at least $50 \%$ of the total myelinated fibers of each nerve. The number of myelinated fibers per nerve was counted directly from glass slides using a Jenaval 250-CF light microscope and camera lucida attachment. The data were analyzed with an unpaired $t$-test. In cases where 
data were not normally distributed or when variances were unequal, data were analyzed with a Mann-Whitney $U$-test.

Cholinesterase assay. Plasma samples were collected from 13 affected LST for determination of cholinesterase. For comparison, plasma was also obtained from 14 clinically healthy captive LST in Florida and North Carolina. All samples were heparinized on collection, and plasma was immediately removed and shipped on dry ice to the University of Florida where they were stored at $-80^{\circ} \mathrm{C}$ until analyzed. Cholinesterase levels were determined in duplicate for each turtle according to the instructions of a commercially available immunoassay (Sigma Diagnostics, Procedure No. 420). The results were recorded as Rappaport (Rapp) U ml-1 plasma.

Heavy metal assays. We assayed 15 metals (aluminum [Al], arsenic [As], cadmium [Cd], chromium $[\mathrm{Cr}]$, copper $[\mathrm{Cu}]$, iron $[\mathrm{Fe}]$, lead $[\mathrm{Pb}]$, manganese [Mn], mercury [Hg], molybdenum [Mo], nickel [Ni], selenium [Se], silver [Ag], thallium [Tl] and zinc [Zn]) in matched liver and kidney tissues of 9 affected LST. For comparison, tissue samples collected from a female LST that had died of an unrelated health problem 2 yr prior to the epizootic were also analyzed. For quality control, standard reference material 1577b (bovine liver; National Institute of Standards \& Technology, Gaithersburg, Maryland) was prepared and analyzed alongside samples.

Tissue samples were homogenized, weighed and pre-digested in nitric acid and hydrogen peroxide for all metals except total $\mathrm{Hg}$, which was digested in a warmed solution of concentrated sulfuric and nitric acids with potassium permanganate followed by an addition of potassium persulfate. Analysis for $\mathrm{Al}, \mathrm{As}$, $\mathrm{Cd}, \mathrm{Cr}, \mathrm{Cu}, \mathrm{Fe}, \mathrm{Pb}, \mathrm{Mn}, \mathrm{Hg}, \mathrm{Mo}, \mathrm{Ni}, \mathrm{Se}, \mathrm{Ag}, \mathrm{Tl}$, and $\mathrm{Zn}$ was by inductively-coupled plasma-atomic emission spectroscopy (SW 6010, EPA 220.7; US EPA 1996). Mercury was determined by cold-vapor atomic absorption (EPA 7471A; US EPA 1996). All results are reported in $\mathrm{mg} \mathrm{kg}^{-1}$ dry weight. Dry weight values were obtained by freeze-drying tissue samples.

Microalgal toxicology. Kidney, liver, lung, urine and stomach contents from 20 LST were tested for the neurotoxins brevetoxins (PbTx), ciguatoxin (CTX) (Florida Wildlife Research Institute [FWRI], St. Petersburg), domoic acid and palytoxin (NOAA Center for Coastal Environmental Health \& Biomolecular Research, Charleston) as well as for protein phosphatase inhibition (FWRI). Samples were extracted twice in 100\% acetone $(1: 2 \mathrm{w} / \mathrm{v})$. The pooled acetone extracts were evaporated to dryness, redissolved in $80 \%$ methanol, and partitioned twice with hexane. The methanol fraction was then evaporated to dryness and redissolved in $100 \%$ methanol. Urine samples were clarified by cen- trifugation and extracted with C18 solid-phase extraction columns (1 g; SupelcoDiscovery, Sigma-Aldrich). The livers of 7 turtles were also tested for saxitoxin (FWRI). Samples were extracted using $0.1 \mathrm{~N} \mathrm{HCl}$, adjusted to $\mathrm{pH} 2.5$ to 4 , boiled for $5 \mathrm{~min}$ in a boiling water bath, and then centrifuged at $3000 \times g$ for $10 \mathrm{~min}$.

Competitive ELISA assays to detect brevetoxins (PbTx) were performed according to Naar et al. (2002). This assay recognizes all congeners and metabolites of brevetoxin that have a PbTx-2-type backbone. The lower limit of quantification was $5 \mathrm{ng} \mathrm{g}^{-1}$ of tissue (5 $\mathrm{ng} \mathrm{ml} \mathrm{m}^{-1}$ for urine). Receptorbinding assays were performed according to Van Dolah et al. (1994) to detect brevetoxins and/or ciguatoxins. This assay detects anything that binds to Site 5 on the voltage-dependent sodium channel, and so would detect ciguatoxins as well as brevetoxins. The lower limit of quantification was approximately $30 \mathrm{ng} \mathrm{g}^{-1}$ of tissue (30 $\mathrm{ng} \mathrm{ml}^{-1}$ for urine). Tissue samples were also tested for brevetoxin (North Carolina State University, Raleigh) using micellar electrokinetic capillary chromatography with laser-induced fluorescence detection (MEKC-LIF; Shea 1997). Extracts were also analyzed for okadaic acid (and other protein phosphatase inhibitors) using a colorimetric protein-phosphatase inhibition assay modified from Tubaro et al. (1996). Portions of stomach contents and urine samples were screened for domoic acid and palytoxin (NOAA). Receptor-binding assays were performed according to Van Dolah et al. (1994) to detect domoic acid, and a modified hemolysis assay was used to screen for palytoxin). Extracts of liver were tested for saxitoxin using a previously described, direct ELISA, with a lower limit of quantification of $10 \mathrm{ng} \mathrm{g}^{-1}$ (Usleber et al, 1991).

Environmental data. Environmental and harmful algal bloom data were reviewed for incidental water samples collected by FWRI from south Florida.

\section{RESULTS}

\section{Stranding data}

From October 2000 to March 2001, 49 live, debilitated LST were found throughout coastal waters of southern Florida, from Manatee County on the west coast to Palm Beach County on the east coast (Fig. 1). Most (34) were found in the Florida Keys (Monroe County). More than $75 \%$ of the affected LST were found from November 2000 to January 2001; 39 of a total of 49). The $10 \mathrm{~cm}$ size class distribution of affected LST was not different from that of stranded LST in south Florida during the last decade (Fig. 2). However, the number of dead and debilitated LST found during 


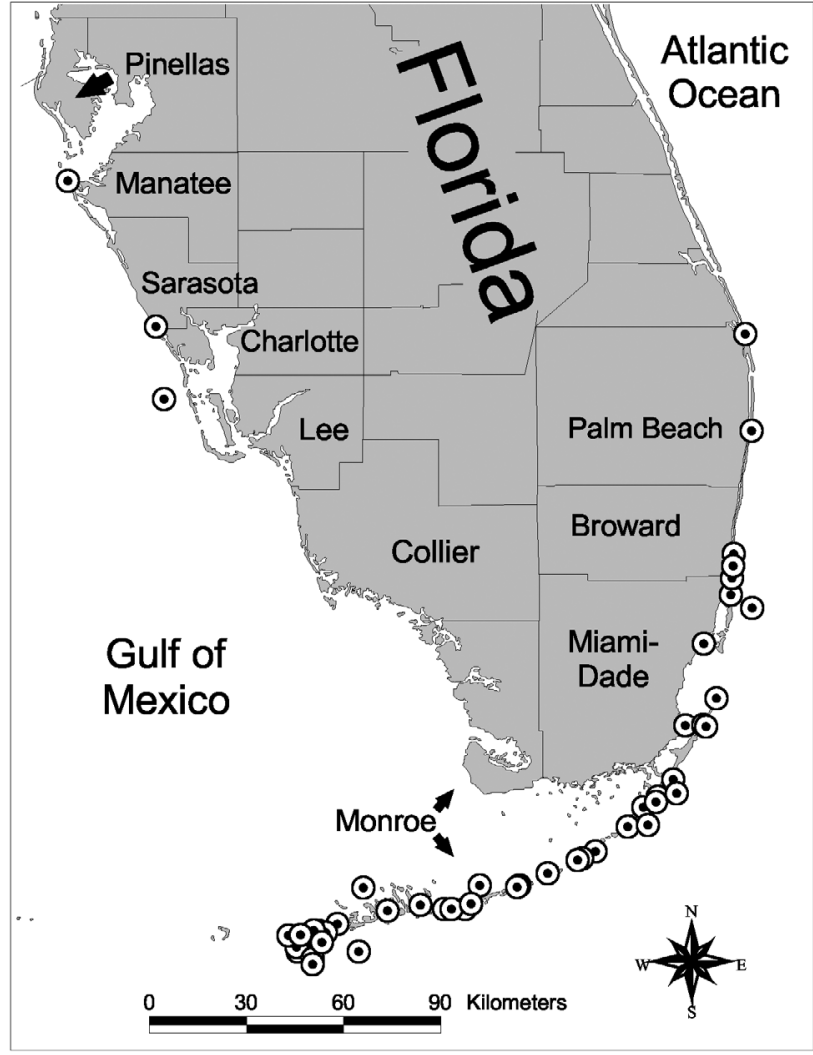

Fig. 1. Locations in Florida where debilitated Caretta caretta associated with epizootic were found between 5 October 2000 and 24 March 2001. Monroe County comprises the triangular piece of land between Collier and Miami-Dade and almost all of the chain of islands (Florida Keys) to the south and southeast

the epizootic (189) was almost 6 times greater than the average number (33) found in south Florida from October through March of each year during the last decade (Fig. 3).

\section{Clinical findings}

Affected LST weighed less then similar-sized clinically healthy LST captured in south Florida (Fig. 4). The major clinical sign observed in the 35 live, debilitated LST submitted to the Turtle Hospital was varying degrees of paresis. The severely affected turtles were unable to move voluntarily, had no corneal, palpebral or menace response, and no swallowing or gag reflex. Deep pain was absent peripherally (distal fore- and pelvic-limbs), but was present proximally (proximal to the humerus-radius-ulnar joint, the femur-tibia-fibula joint, and on the lateral aspects of the cervical region). Major hematologic and plasma biochemical findings were compared to published hematologic (Bradley et

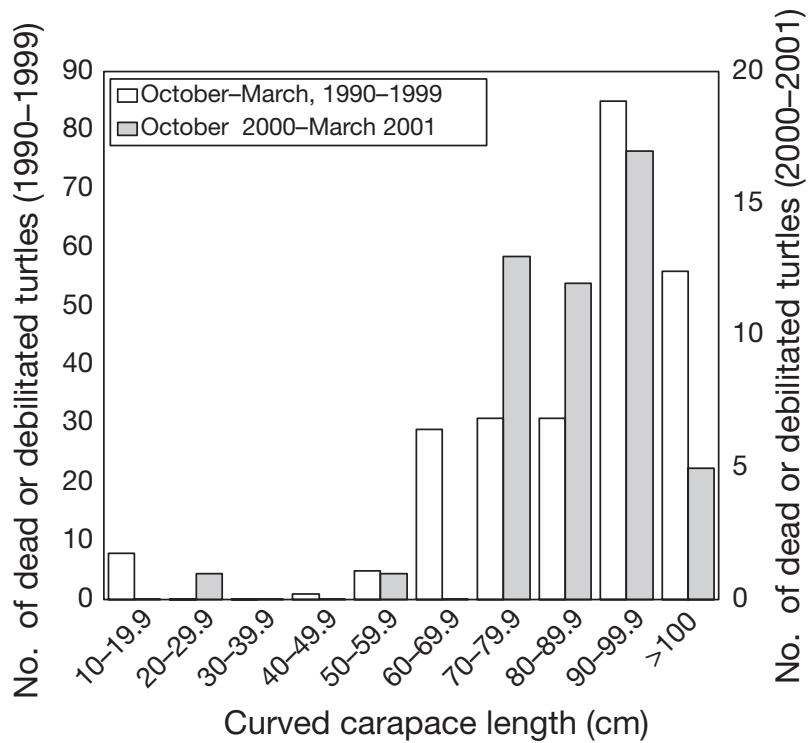

Fig. 2. Caretta caretta. Size class distribution of debilitated loggerhead sea turtles (LST) associated with the epizootic (2000 to 2001) and of dead or debilitated LST found from October to March during the previous 10 yr (1990 to 1999) in south Florida (Manatee County to Palm Beach County). There was no difference in carapace lengths between the 2 groups (Kruskal-Wallis 1-way ANOVA, p > 0.05)

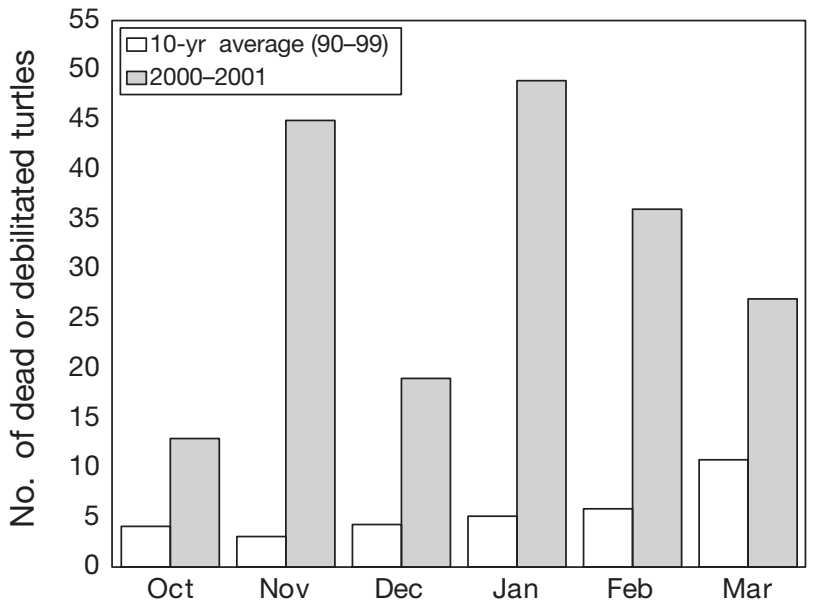

Fig. 3. Caretta caretta. Number LST found dead or debilitated each month from October to March in south Florida (Manatee County to Palm Beach County) during the epizootic (2000 to 2001) and the average number found dead or debilitated in south Florida from October to March each year during the previous 10 yr (1990 to 1999)

al. 1998) and biochemical values (http://accstr.ufl.edu/ blood_chem.htm; Bolten et al. 1992) and included leukocytosis (mean $=12300$ white blood cell count [WBC] $\mathrm{mm}^{-3}$; normal $=4$ to $10 \mathrm{WBC} \mathrm{mm}^{-3}$ ), heterophilia $($ mean $=52 \%$; normal $=$ up to $40 \%)$, and hyperglycemia $\left(\right.$ mean $=211 \mathrm{mg} \mathrm{dl}^{-1}$; normal $=81$ to $102 \mathrm{mg} \mathrm{dl}^{-1}$ ). Most LST had a mucoid respiratory discharge. Bronchoscopy on several LST demonstrated 


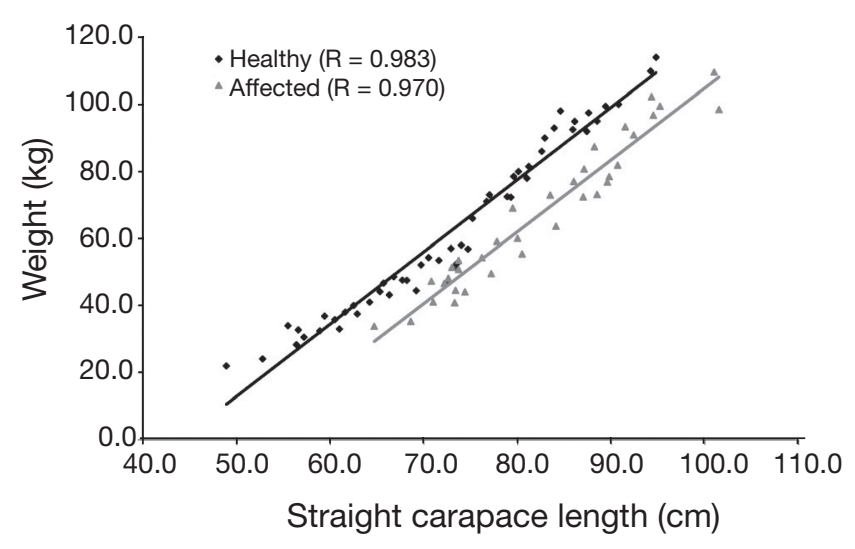

Fig. 4. Caretta caretta. Weight as a function of straight-line carapace length in clinically healthy and affected LST. Healthy LST were captured in south Florida prior to October 2000 during a long-term in-water study of LST in Florida Bay. Slopes of regression lines do not differ $(p>0.05$, Student's $t$-test), but elevations do ( $p<0.001$, Student's $t$-test)

hyperemia, mucoid fluid accumulation and plaques in the trachea and bronchi. In the most severe cases, brownish, caseous material was seen occluding both the upper and the lower airways. A profound bradycardia ( 4 to 8 beats $\mathrm{min}^{-1}$ ) was also identified in 3 of the LST (normal $=28$ to 32 beats $\mathrm{min}^{-1}$ ). Following atropine administration, the heart rate increased to 18 to 26 beats $\mathrm{min}^{-1}$. Atropine was administered twice a day (every $12 \mathrm{~h}$ ) to maintain this heart rate.

Of the 35 LST brought to the Turtle Hospital and treated with a variety of medicants, 31 died. Of the last LST that were admitted to the Turtle Hospital, 4 were released after 5 to 6 mo of rehabilitation; 3 received atropine.

\section{Neurologic examination}

We submitted 3 affected LST to neurological examination. Of these, 2 had clinical signs including depressed mentation, an absent menace-response bilaterally, minimal eye movements and an absent palpebral reflex, reduced jaw tone, inability to chew or swallow, loss of neck retraction and muscle tone, slight to no response to neck superficial nociceptive stimuli, absent limb movements and decreased muscle tone, absent flexor reflexes in all 4 limbs, diminished tail and cloacal reflexes, and no response to sensory stimuli along the carapace or plastron. The third affected LST was recovering and, although very weak, had bilateral palpebral reflexes, reduced but detectable neck retraction, and observable limb movements. Flexor reflexes remained depressed. A righting response could not be elicited in any of the turtles when they were laid on their carapace (dorsal recumbency).
Electromyography, performed in the absence of anesthesia, revealed prolonged insertional activity with an absence of positive sharp waves and fibrillation potentials. Motor unit action potentials, usually found on electromyography in unanesthetized individuals, were rarely identified. An evoked muscle response to stimulation of the sciatic nerve was absent bilaterally. Since an evoked muscle response could not be obtained, motor nerve conduction velocity (MNCV) could not be measured. Of particular note, there was no limb movement or behavior suggesting discomfort during electrophysiological testing in the unanesthetized turtles. A normal LST had an evoked muscle response and MNCV of $48.8 \mathrm{~m} \mathrm{~s}^{-1}$.

\section{Pathology}

The 18 necropsied LST were at rehabilitation facilities for periods ranging from 1 to $65 \mathrm{~d}$ (mean of $29.8 \mathrm{~d}$ ). Despite being force-fed, those turtles that remained alive for several weeks and subsequently died showed muscle atrophy and, at necropsy, had serous atrophy of fat. The gastrointestinal contents of the necrospied LST were collected and examined, and contained little solid material. No mollusk remains were found, and crustacean remains were found in only 3 LST (a single Squilla sp. in 1 LST, pieces of a single small crab in the second LST, and a small portunid crab in the third LST). Crustacean exoskeletons or molluscan shells were not found in the small amount of feces produced while in the rehabilitation facility. Cnidarians and poriferans were better represented in gastrointestinal contents, with many containing nematocysts ( $\mathrm{n}=14)$, jelly-like flesh $(\mathrm{n}=11$ : some could have been from ctenophores), or spicules ( $\mathrm{n}=8$ : one also with pieces of sponge). The sex of affected LST was determined at necropsy to be 2 males and 16 females.

At the beginning of the epizootic, necropsied LST were in fair to good physical condition, with moderate to abundant fat stores, and a prominent paired thymus. Toward the latter part of the epizootic, necropsied LST showed loss of fat stores and muscle mass, and sunken plastrons, and the epibiotic (barnacles) and green and brown algal growth was greater than that seen in healthy turtles. The eyes were markedly sunken within their orbits. Areas of skin within the axillary and inguinal regions were sometimes mottled pink-to-red. The carapace contained locally extensive areas of scaling and crusting that could be peeled off easily. The thymus was approximately $25 \%$ of the expected size. The corneas of some LST were cloudy and associated with a fibrin plaque on the epithelial surface. Gross lesions seen in the digestive tract included esophageal dilatation and focal 1 to $3 \mathrm{~cm}$ diameter tan to dark brown, raised 
fibrinous plaques on the mucosa surface of the oropharynx, esophagus, stomach and intestine. In 3 turtles, the trachea was lined with a yellow/green to grey/tan friable, rubbery membrane that almost entirely occluded the tracheal lumen in multiple areas. The meninges of the brain in 1 LST was diffusely reddened.

A dissecting microscope revealed numerous, minimally raised, tan to black 1 to $4 \mathrm{~mm}$ diameter nodules on the meningeal surfaces of the brain (11 of 11) and spinal cord (10 of 10) of affected LST (Fig. 5). Then nodules consisted of 40 to $53 \times 32$ to $38 \mu \mathrm{m}$-diameter, dark brown, ellipsoidal, spirorchiid trematode eggs consistent with those of Neospirorchis sp. (Price 1934, Manter \& Larson 1950, Wolke et al. 1982) (Fig. 6). Their relative numbers ranged from scattered single eggs in vessels to masses of eggs probably numbering thousands. We dissected 1 or more $2 \mathrm{~cm}$, threadlike, transparent adult spirorchiids with black internal viscera and dark serpentine gastrointestinal tracts from meningeal vessels of 2 of 11 LST brains and 1 of 10 spinal cords; they were and identified as Neospirorchis sp. (Price 1934, Manter \& Larson 1950). While adult Carettacola sp. were recovered from visceral vessels in 2 of the affected LST, neither adults nor their eggs were recovered from CNS tissues.

Histologically, all 18 LST had spirorchiid trematode eggs in their brain (Table 1). While spirorchiid eggs were not counted in the CNS of each turtle to determine numbers $\mathrm{g}^{-1}$ tissue, affected turtles tended to have more eggs per tissue section than the archived CNS samples of the control group. Of the affected LST, 6 were categorized as Grade 1, 8 as Grade 2, and 4 as Grade 3. Of the control LST, 3 were Grade 0, 9 were Grade 1, and 1 was Grade 2; none were Grade 3. Spirorchiid eggs measuring 46 to $53 \mu \mathrm{m}$, oval to globular to hollow, and with a hyaline tan to yellow/brown

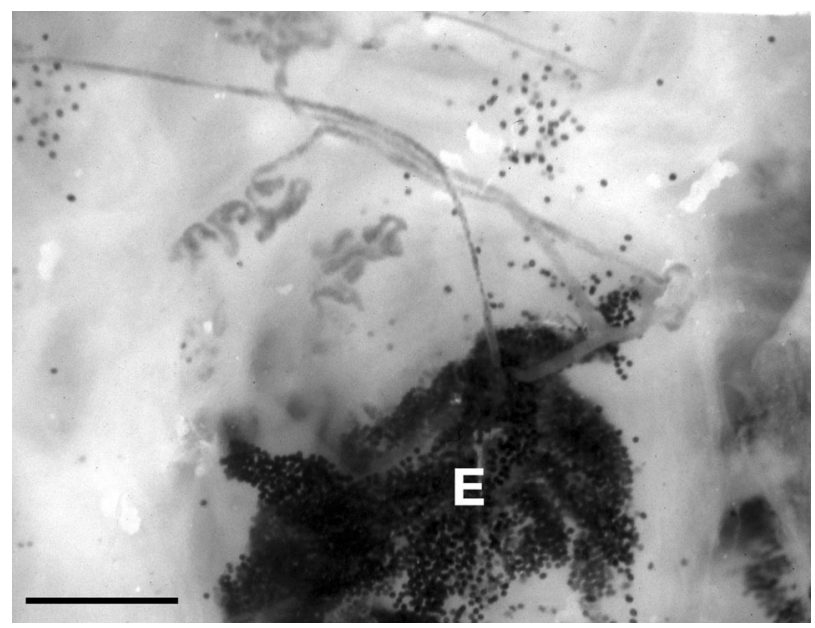

Fig. 5. Caretta caretta. Dorsal surface of brain showing eggs (E) of Neospirorchis sp. within meninges. Scale bar $=1 \mathrm{~mm}$

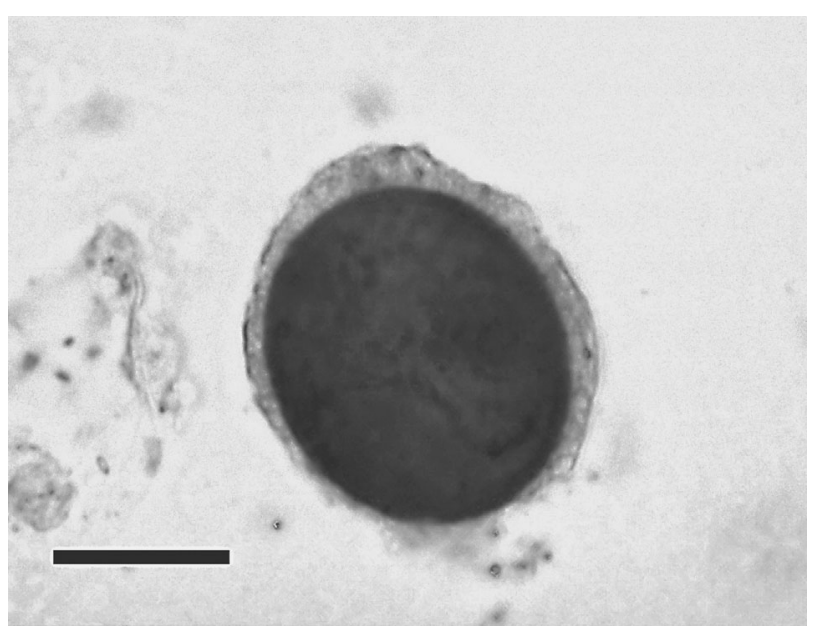

Fig. 6. Neospirorchis sp. egg from brain of Caretta caretta. Scale bar $=25 \mu \mathrm{m}$

wall, were present within or adjacent to capillaries in white and gray matter of the brain. Multifocally, the eggs were often encompassed by granulomas comprised of multinucleated giant cells (Fig. 7). Eggs and small granulomas were also scattered throughout the meninges (Fig. 8). Elsewhere, there were perivascular aggregates of macrophages with cytoplasmic, refractile, pale-tan granules (egg fragments). In some areas of the white matter, there was marked gliosis with frequent satellitosis. Increased numbers of mononuclear cells were present in the Virchow-Robins' spaces of multiple capillaries. In addition, multiple capillaries within the meninges of the brain of 7 LST contained cross sections through spirorchiid trematodes (Fig. 9). Associated with these parasites, were mild to moderate multifocal infiltrates of lymphocytes in the meninges, often accompanied by fibrosis and mineralization; the meningeal space was multifocally widened by edema fluid. Only 1 of 13 control LST had adult spirorchiid trematodes in the meninges of the brain.

Of 18 affected LST, 15 had spirorchiid eggs in the spinal cord. Of these, 9 were Grade 1, 5 were Grade 2 and 1 was Grade 3. Only 1 of 4 control LST had spirorchiid eggs (Grade 1) in the spinal cord. Adult spirorchiids were seen in the spinal cord meninges of 3 affected LST. No adult spirorchiids were seen in the meninges of the spinal cord of 4 control LST.

A variety of additional lesions affecting multiple organs also were found and are listed in Table 1.

\section{Muscle histology and histochemistry}

Pathological changes in paraffin-embedded muscle specimens included vasculitis (2), thrombosis (1) and spirochiid eggs (2). In a few turtles, there were dark 


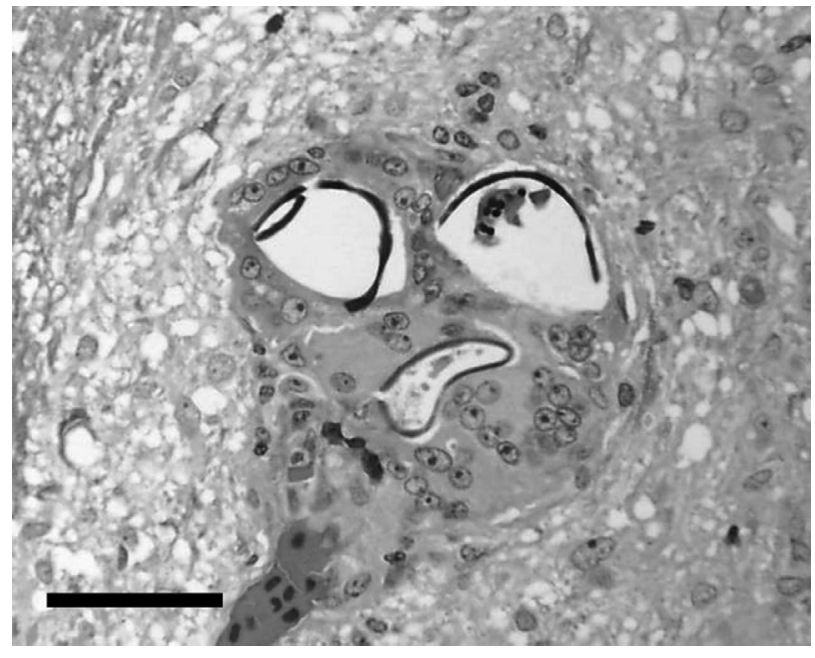

Fig. 7. Caretta caretta. Microgranuloma within gray matter of brain containing eggs of Neospirorchis sp. H\&E, scale bar = $50 \mu \mathrm{m}$

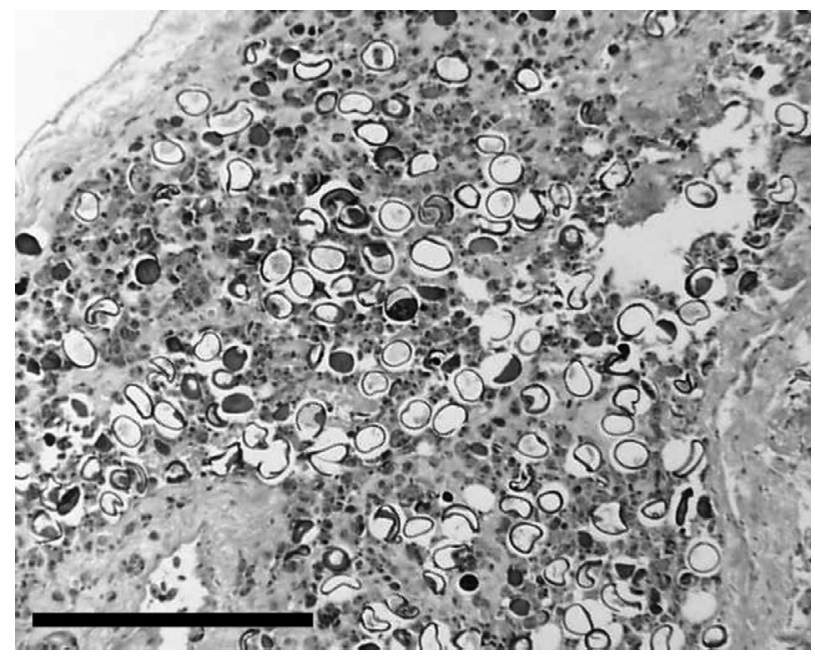

Fig. 8. Neospirorchis sp. eggs within meninges of Caretta caretta. H\&E, scale bar $=200 \mu \mathrm{m}$

red foci comprised of degenerate, necrotic or atrophied muscle fibers encompassed by a mixed infiltrate of heterophils, macrophages and lymphocytes. Within the frozen muscle biopsy sections, the myofiber size of affected LST was similar to that of controls; no obvious neurogenic atrophy was seen. Compared to control individuals, no abnormalities were found in any of the histochemical stains and reactions.

\section{Peripheral nerve histology, morphometry and electron microscopy}

Paraffin sections of sciatic nerve, brachial plexus, optic chiasm and cranial nerves were examined in

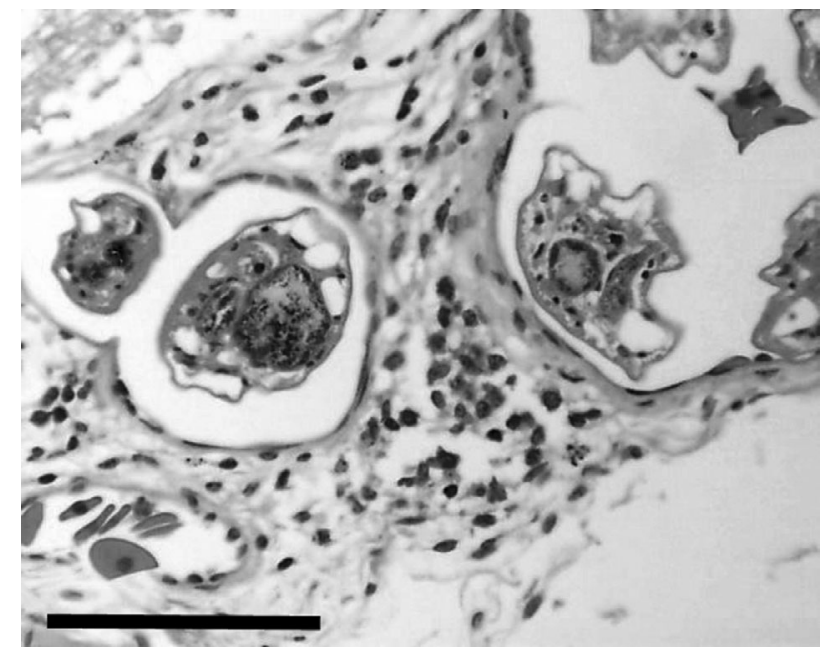

Fig. 9. Neopsirorchis sp. adult within meningeal blood vessels of brain of Caretta caretta. H\&E, scale bar $=50 \mu \mathrm{m}$

14 of the 18 turtles with neurospirorchiidiasis. Pathological changes were most prominent within the epineurium, and included mild to focally moderate infiltrates of lymphocytes, sometimes centering on capillaries. Occasional trematode eggs, sometimes within a granuloma, were present in capillaries.

The predominant abnormality identified within resin-embedded peripheral nerve specimens from affected LST was demyelination (Fig. 10A,B). Occasional myelinated fibers with inappropriately thin sheaths were also evident, suggestive of remyelination. Axonal degeneration was not observed. Additionally, subperineural edema was evident in nerves from 4 of 7 affected LST. Morphometric analysis demonstrated that myelinated nerve-fiber density was not significantly different between nerves from affected turtles and unaffected controls; however, there was a significant decrease in the mean axonal diameter $(\mathrm{p}<$ 0.02), and a shift in the population of fibers to smaller diameters with a significant reduction in numbers of larger-diameter fibers ( $\mathrm{p}<0.02$; Table 2 ). Ultrastructural examination was also consistent with a demyelinating neuropathy (Fig. 10C,D).

\section{Cholinesterase assay}

Plasma cholinesterase activity was determined for healthy captive LST and for LST impacted by the mortality event. For the healthy individuals ( $\mathrm{n}=12$ ), the mean activity was 30.20 Rapp $\mathrm{U} \mathrm{ml}^{-1}$ with a

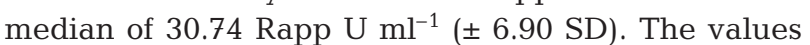
ranged from a minimum of 18.10 to a maximum of 43.60 Rapp $\mathrm{U} \mathrm{ml}^{-1}$. For the affected individuals ( $\mathrm{n}=$ 
Table 1. Caretta caretta. Lesions found in multiple organs of 18 loggerhead sea turtles with clinical signs of neurological disease. GI: gastrointestinal tract. Values are numbers of turtles with lesions; -: not applicable for this organ listed

\begin{tabular}{|c|c|c|c|c|c|c|c|c|c|c|}
\hline Lesion & Brain & $\begin{array}{l}\text { Spinal } \\
\text { cord }\end{array}$ & Nerves & $\begin{array}{l}\text { Skeletal } \\
\text { mus }\end{array}$ & Heart & $\begin{array}{l}\text { Respiratory } \\
\text { tract }\end{array}$ & Liver & Spleen & Kidney & GI \\
\hline Intralesional ova & 18 & 15 & 8 & 2 & 10 & 12 & 6 & 13 & 6 & 14 \\
\hline Intralesional adult trematodes & 7 & 3 & 0 & 0 & 2 & 0 & 1 & 0 & 0 & 3 \\
\hline Granulomatous inflammation & 9 & 2 & 1 & 0 & 4 & 3 & 3 & 4 & 1 & 6 \\
\hline Mixed leukocytic inflammation & 10 & 7 & 5 & 4 & 13 & 16 & 8 & 5 & 6 & 18 \\
\hline Vasculitis & 1 & 1 & 4 & 2 & 0 & 0 & 0 & 1 & 1 & 1 \\
\hline Edema & 8 & 8 & 13 & 9 & 5 & 13 & 0 & 0 & 3 & 8 \\
\hline Necrosis & 2 & 1 & 0 & 6 & 0 & 3 & 1 & 1 & 2 & 2 \\
\hline $\begin{array}{l}\text { Degeneration } \\
\text { (axonal, muscular or parenchymal) }\end{array}$ & 1 & 5 & 2 & 13 & 5 & - & 2 & - & 2 & - \\
\hline Fibrosis (meningeal or stromal) & 3 & 1 & 1 & 2 & 5 & 1 & 7 & 0 & 4 & 4 \\
\hline Hemorrhage & 0 & 1 & 0 & 2 & 1 & 1 & 0 & 0 & 0 & 0 \\
\hline Intralesional cestode cysts & - & - & - & - & - & - & - & - & - & 5 \\
\hline Thrombosis & 0 & 0 & 0 & 1 & 1 & 0 & 0 & 0 & 1 & 1 \\
\hline Mineralization (including meningeal) & 2 & 2 & 0 & 1 & 0 & 0 & 0 & 0 & 3 & 0 \\
\hline $\begin{array}{l}\text { Atrophy } \\
\text { (muscular, lymphoid or parenchymal) }\end{array}$ & 0 & 0 & 0 & 10 & 0 & 0 & 1 & 6 & 0 & - \\
\hline Intralesional bacteria & 0 & 0 & 0 & 1 & 0 & 3 & 0 & 0 & 0 & 2 \\
\hline Hyperplasia (intimal or epithelial) & - & - & - & - & 1 & 6 & 1 & 0 & 0 & 2 \\
\hline Serositis & - & - & - & - & 1 & 0 & 0 & 1 & 0 & 6 \\
\hline Fibrinonecrotic inflammation & 0 & 0 & 0 & 0 & 0 & 4 & 0 & 0 & 0 & 2 \\
\hline Lipidosis & - & - & - & 0 & 0 & - & 2 & - & 0 & - \\
\hline Syncytia formation & - & - & - & - & - & 3 & - & - & - & - \\
\hline Ulceration & - & - & - & - & - & 1 & - & - & - & 1 \\
\hline Intralesional fungi & 0 & 0 & 0 & 0 & 0 & 5 & 0 & 0 & 0 & 1 \\
\hline Reactive melanocytic centers & - & - & - & - & - & - & 13 & 3 & - & - \\
\hline Hemosiderosis & 0 & 0 & 0 & 0 & 0 & 0 & 5 & 0 & 0 & 0 \\
\hline Not examined & 0 & 3 & 4 & 0 & 1 & 0 & 0 & 1 & 0 & 0 \\
\hline No significant lesions & 0 & 0 & 1 & 0 & 2 & 1 & 0 & 1 & 4 & 0 \\
\hline
\end{tabular}

13), the mean activity was 28.37 Rapp $\mathrm{U} \mathrm{ml}^{-1}$ with a median of 29.97 Rapp $\mathrm{U} \mathrm{ml}^{-1}( \pm 5.10 \mathrm{SD})$. The values ranged from a minimum of 15.80 to a maximum of 35.25 Rapp $\mathrm{U} \mathrm{ml} \mathrm{ml}^{-1}$; 2 samples from apparently healthy LST gave activities below the assay quantitation limit (10 Rapp $\mathrm{U} \mathrm{ml}^{-1}$ ). Because of the reported health of the turtles and to the relative ease with which cholinesterase may be inactivated (elevated temperature or chemical exposure), these sample values were excluded from the data set. These assay results showed no significant difference between blood cholinesterase levels of normal and affected LST.

\section{Heavy metals}

Of the 15 metals assayed, 8 (As, Cd, Cu, Fe, Mn, Se, $\mathrm{Zn}, \mathrm{Hg}$ ) were present in both liver and kidney at detectable levels for all LST (Table 3). The average $( \pm \mathrm{SD})$ percentage moisture was $72.00 \pm 7.14$ for liver and $78.78 \pm 4.55$ for kidney tissues.

As expected, the averaged concentrations for all but As, Cd and $\mathrm{Tl}$ were lower in the kidney than in the liver; these trends, however, did not hold consistently when tissues of individual turtles were considered. Typically, higher levels of $\mathrm{As}, \mathrm{Cd}$ and $\mathrm{Pb}$ are expected in the kidney than in the liver, but in 2 turtles this trend was reversed (for all metals in one turtle, and for As alone in the other). $\mathrm{Cu}, \mathrm{Fe}$ and $\mathrm{Se}$ followed the expected trends (highest concentration in the liver), and were quantified in all tissue samples. In contrast, $\mathrm{Cr}, \mathrm{Mn}, \mathrm{Zn}$ and $\mathrm{Hg}$ each were generally found at higher levels in the liver than in the kidney, except in the tissues of a few specific individuals. Although Ag, $\mathrm{Al}, \mathrm{Mo}$ and $\mathrm{Ni}$ were not often detected in this set of samples, all were present in the tissues of a single LST, with a second having $\mathrm{Ag}$, Mo and $\mathrm{Ni}$ at quantifiable levels and 2 others having $\mathrm{Al}$. $\mathrm{Tl}$, not detectable in the liver, was quantified in 6 of 9 renal samples.

\section{Micoalgal toxicology}

Of the 20 loggerheads analyzed, 7 tested positive for brevetoxins by competitive ELISA. In 3 of these, more than 1 tissue type was positive. Values ranged from 3.6 to $26.5 \mathrm{ng} \mathrm{g}^{-1}$ (Table 4). The majority of positive 

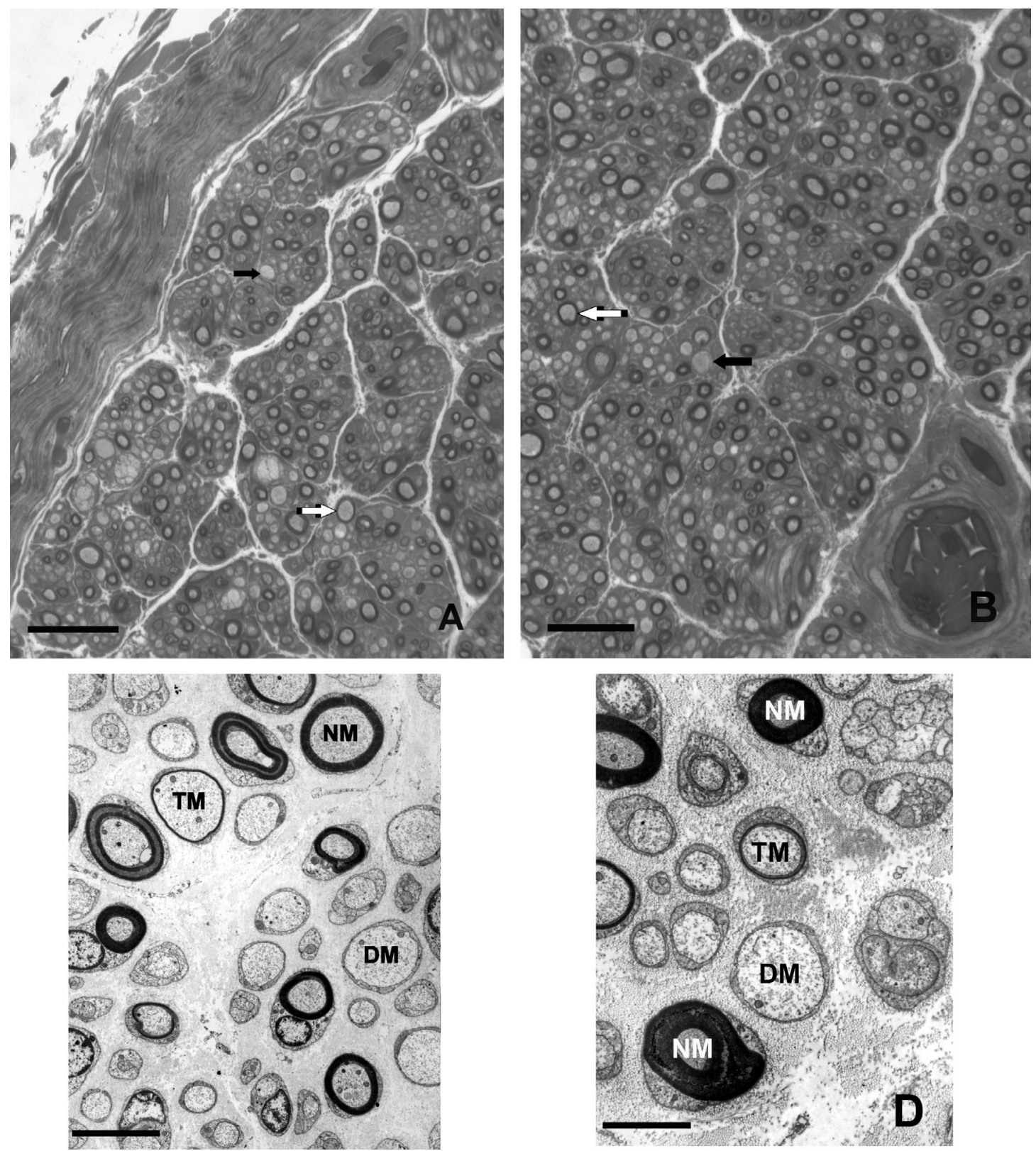

Fig. 10. Caretta caretta. Thick sections $(1 \mu \mathrm{m})$ showing the (A) subperineurial and (B) centrofascicular regions of a sciatic nerve from an affected loggerhead sea turtle. In both regions, numerous demyelinated fibers are evident (black arrows). Scattered throughout are several inappropriately thinly myelinated fibers (white arrows), suggestive of early remyelination. Toluidine blue; scale bars $=250 \mu \mathrm{m}$. In transmission electron micrographs $(\mathrm{C})$, a field contains numerous completely demyelinated axons (DM) and several axons with inappropriately thin myelin sheaths (TM) relative to the axon caliber, as well as several fibers with myelin sheaths of more normal thickness (NM). Uranyl acetate and lead citrate; scale bar $=2 \mu \mathrm{m}$. At higher magnification (D), a thinly myelinated fiber (TM) and a demyelinated fiber (DM) are similarly shown for comparison with myelin of relatively normal thickness (NM). Uranyl acetate and lead citrate; scale bar $=1 \mu \mathrm{m}$

samples were from the liver and stomach contents (Fig. 11).

Samples showed negative for microalgal toxins by all other methods. The levels of PbTx found by ELISA were below the detection limit for the receptor-binding assay. Because CTX also binds to the same Site 5 chan- nel in the receptor-binding assay, this assay was also negative for CTX. No PbTx were detected by MEKCLIF, however that method is specific for PbTx-2, PbTx3, cysteinyl PbTx-3 and oxidized cysteinyl PbTx-3. The competitive ELISA may be detecting other PbTx metabolites. 
Table 2. Caretta caretta. Morphometric assessment of myelinated fibers in the sciatic nerve. Values are means \pm SD $(n=5$ unaffected and 7 affected turtles, respectively) and were analyzed with an unpaired $t$-test. When SDs were unequal, data were analyzed with a Mann-Whitney $U$-test. ns: not significant

\begin{tabular}{|c|c|c|c|c|c|}
\hline & \multirow[t]{2}{*}{$\begin{array}{l}\text { No. per } \\
\text { nerve }\end{array}$} & \multirow[t]{2}{*}{$\begin{array}{l}\text { Mean axonal } \\
\text { diam. }(\mu \mathrm{m})\end{array}$} & \multicolumn{3}{|c|}{$\begin{array}{l}\text { Relative frequency of } \\
\text { fibers with diameters }\end{array}$} \\
\hline & & & $\leq 3 \mu \mathrm{m}$ & $>3$ and $\geq 7 \mu \mathrm{m}$ & $>7 \mu \mathrm{m}$ \\
\hline Unaffected & $5998 \pm 2291$ & $4.65 \pm 0.70$ & $25.9 \pm 9.4$ & $59.4 \pm 6.0$ & $14.7 \pm 8.3$ \\
\hline Affected & $\begin{array}{c}5037 \pm 2424 \\
\mathrm{~ns}\end{array}$ & $\begin{array}{l}3.61 \pm 0.60 \\
p<0.02\end{array}$ & $\begin{array}{l}42.8 \pm 15.9 \\
\text { ns }\end{array}$ & $\begin{array}{l}52.4 \pm 13.3 \\
\mathrm{~ns}\end{array}$ & $\begin{array}{l}4.9 \pm 3.4 \\
p<0.02\end{array}$ \\
\hline
\end{tabular}

Table 3. Caretta caretta. Heavy metal concentrations (mg kg-1 dry wt) in liver and kidney tissues of 1 unaffected LST and 9 LST with neurological disease. Values are means $\pm \mathrm{SD}$ (no. of detecable samples) and range of concentrations. BDL: below detection limit

\begin{tabular}{|c|c|c|c|c|}
\hline \multirow[t]{2}{*}{ Metal } & \multicolumn{2}{|c|}{ Liver } & \multicolumn{2}{|c|}{ Kidney } \\
\hline & $\begin{array}{l}\text { Unaffected } \\
\qquad(\mathrm{n}=1)\end{array}$ & $\begin{array}{c}\text { Affected } \\
(\mathrm{n}=9)\end{array}$ & $\begin{array}{l}\text { Unaffected } \\
\qquad(\mathrm{n}=1)\end{array}$ & $\begin{array}{c}\text { Affected } \\
(\mathrm{n}=9)\end{array}$ \\
\hline $\mathrm{Ag}$ & BDL & $\begin{array}{c}3.24 \pm 0.60(2) \\
\text { BDL-3.66 }\end{array}$ & BDL & $\begin{array}{l}\text { BDL (0) } \\
\text { BDL }\end{array}$ \\
\hline $\mathrm{Al}$ & BDL & $\begin{array}{c}20.2 \pm 12.0(3) \\
\text { BDL-29.8 }\end{array}$ & BDL & $\begin{array}{l}\text { BDL (0) } \\
\text { BDL }\end{array}$ \\
\hline As & 4.07 & $\begin{array}{c}46.5 \pm 38.3(9) \\
7.35-132\end{array}$ & 6.69 & $\begin{array}{c}75.8 \pm 49.2(9) \\
8.91-164\end{array}$ \\
\hline $\mathrm{Cd}$ & 16.0 & $\begin{array}{c}39.5 \pm 29.4(9) \\
13.2-105\end{array}$ & 51.8 & $\begin{array}{c}142 \pm 65.8(9) \\
70.7-293\end{array}$ \\
\hline $\mathrm{Cr}$ & BDL & $\begin{array}{c}9.23 \pm 8.01(9) \\
2.37-25.6\end{array}$ & BDL & $\begin{array}{c}3.49 \pm 0.77(3) \\
\text { BDL-4.05 }\end{array}$ \\
\hline $\mathrm{Cu}$ & 84.3 & $\begin{array}{c}53.2 \pm 32.0(9) \\
10.2-111\end{array}$ & 6.17 & $\begin{array}{c}6.72 \pm 2.50(9) \\
1.70-9.51\end{array}$ \\
\hline $\mathrm{Pb}$ & 5.79 & $\begin{array}{c}11.4 \pm 12.0(2) \\
\text { BDL-19.9 }\end{array}$ & 6.69 & $\begin{array}{c}4.64 \pm 1.37(8) \\
\mathrm{BDL}-6.47\end{array}$ \\
\hline $\mathrm{Fe}$ & 3032 & $\begin{array}{c}9254 \pm 8666(9) \\
2118-28038\end{array}$ & 848 & $\begin{array}{c}304 \pm 333(9) \\
70.7-1131\end{array}$ \\
\hline $\mathrm{Mn}$ & 6.36 & $\begin{array}{c}20.8 \pm 16.5(9) \\
7.27-58.0\end{array}$ & 5.47 & $\begin{array}{c}6.42 \pm 2.34(9) \\
3.63-11.9\end{array}$ \\
\hline Mo & BDL & $\begin{array}{c}12.0(1) \\
\text { BDL-12.0 }\end{array}$ & BDL & $\begin{array}{c}4.05(1) \\
\text { BDL-4.05 }\end{array}$ \\
\hline $\mathrm{Ni}$ & BDL & $\begin{array}{c}4.65(1) \\
\text { BDL-4.65 }\end{array}$ & BDL & $\begin{array}{c}3.33 \pm 0.68(2) \\
\text { BDL-3.82 }\end{array}$ \\
\hline $\mathrm{Se}$ & 26.3 & $\begin{array}{c}95.4 \pm 120(9) \\
15.9-397\end{array}$ & 15.4 & $\begin{array}{c}27.9 \pm 23.1(9) \\
8.05-66.0\end{array}$ \\
\hline $\mathrm{Tl}$ & BDL & $\begin{array}{c}\text { BDL (0) } \\
\text { BDL }\end{array}$ & BDL & $\begin{array}{c}4.95 \pm 1.11(6) \\
\text { BDL-6.97 }\end{array}$ \\
\hline $\mathrm{Zn}$ & 107 & $\begin{array}{c}140 \pm 59.4(9) \\
86.4-288\end{array}$ & 97.6 & $\begin{array}{c}133 \pm 55.0(9) \\
73.5-257\end{array}$ \\
\hline $\mathrm{Hg}$ & 8.57 & $\begin{array}{c}10.2 \pm 8.93(9) \\
0.58-27.4\end{array}$ & 0.52 & $\begin{array}{c}5.64 \pm 8.42(9) \\
0.29-26.3\end{array}$ \\
\hline
\end{tabular}

\section{Environmental data}

Satellite-imagery data indicated increased chlorophyll levels, that were verified in water samples as the red-tide organisms Karenia brevis and K. papilionacea (FWRI data posted at www.floridamarine.org) in the vicinity of the Marquesas/lower Florida Keys area during the period of loggerhead mortality. High cell concentrations were found during January and February 2001. However, there was no relationship between the distribution of PbTx in LST tissues, stranding locations, and the distribution of the red tide.

\section{DISCUSSION}

The number of dead or debilitated LST found during the epizootic was considered a minimum value, since not all affected LST would have been discovered, reported and documented. Additionally, because debilitated LST and carcasses may be transported long distances by currents (Epperly et al. 1996), their locations at the time of discovery may not represent the location of LST at the time of death or debilitation. However, given the observation that many of the LST appeared to be acutely debilitated, we believe the distribution of stranded LST roughly identified the area of the epizootic.

There were 189 stranded LST documented in south Florida (Palm Beach County through Manatee County) during the epizootic, a much greater number than the previous $10 \mathrm{yr}$-average for the same time and place (yearly mean = 33). After determining that no other unusual mortality factors appeared to have occurred during the epizootic, we estimated that 156 (189 minus 33) of the strandings were probably attributable to the epizootic. Furthermore, the stranded LST may represent as little as $7 \%$ of the at-sea mortality of sea turtles (Epperly et al. 1996). Extrapolating this data, we estimated the overall mortality associated with the epizootic to be anywhere between 156 to 2229 turtles. During the $2 \mathrm{yr}$ (April 2001 to March 2003) following the main period of the epizootic, 14 debilitated LST were found with signs of neurological disease similar to that seen during the epizootic (Table 5). In August and September 2004, 4 cases were seen by one of us (C. Manire). The new cases were confined to the same general area of south Florida and most occurred at a similar time of the year.

Affected LST were brought into a rehabilitation facility, where they were weighed and their SCL measured. When the body weights were expressed as a function of their SCL and compared to the same parameters for healthy LST, the affected LST were found to weigh less then similar-sized, clinically healthy LST. This indicated that the affected turtles had not been feeding for a period of time before being found. While we do not have scientific data to calculate the rate of weight loss 
Table 4. Caretta caretta. LST tissues screened for brevetoxins by ELISA. -: no sample available. Values are $\mathrm{ng} \mathrm{g}^{-1}$; BDL: below detection limit

\begin{tabular}{|lccccc|}
\hline Turtle ID & Urine & $\begin{array}{c}\text { Stomach } \\
\text { contents }\end{array}$ & Liver & Kidney & Lung \\
\hline BJA001227-01 & - & - & BDL & BDL & - \\
BJA010117-01 & - & BDL & 7.7 & BDL & - \\
SAS001201-01 & BDL & 5.3 & 7.7 & BDL & BDL \\
CXC001128-01 & BDL & BDL & BDL & BDL & BDL \\
CXR010131-01 & - & BDL & BDL & BDL & BDL \\
SAS010113-02 & - & BDL & BDL & BDL & BDL \\
SAS010107-01 & BDL & BDL & BDL & BDL & BDL \\
CXR01020202 & - & 5.1 & BDL & BDL & - \\
JAW001125-01 & - & BDL & BDL & BDL & - \\
CXR01020301 & - & BDL & 26.5 & 6.2 & BDL \\
SAS001117-01 & & - & BDL & BDL & BDL \\
CAC010211-02 & BDL & - & BDL & BDL & BDL \\
CAC010226-01 & 10.4 & 21.1 & 19.3 & 4.5 & BDL \\
CXR010129-01 & BDL & BDL & 14.5 & BDL & BDL \\
CAC010131-01 & - & - & BDL & BDL & BDL \\
SAS010210-01 & BDL & 6.7 & 9.7 & BDL & BDL \\
SAS010223-01 & BDL & BDL & BDL & BDL & BDL \\
SAS010111-01 & - & - & BDL & BDL & BDL \\
SAS010110-01 & 3.6 & BDL & BDL & BDL & BDL \\
MSCC0104 & - & BDL & BDL & BDL & BDL \\
\hline
\end{tabular}

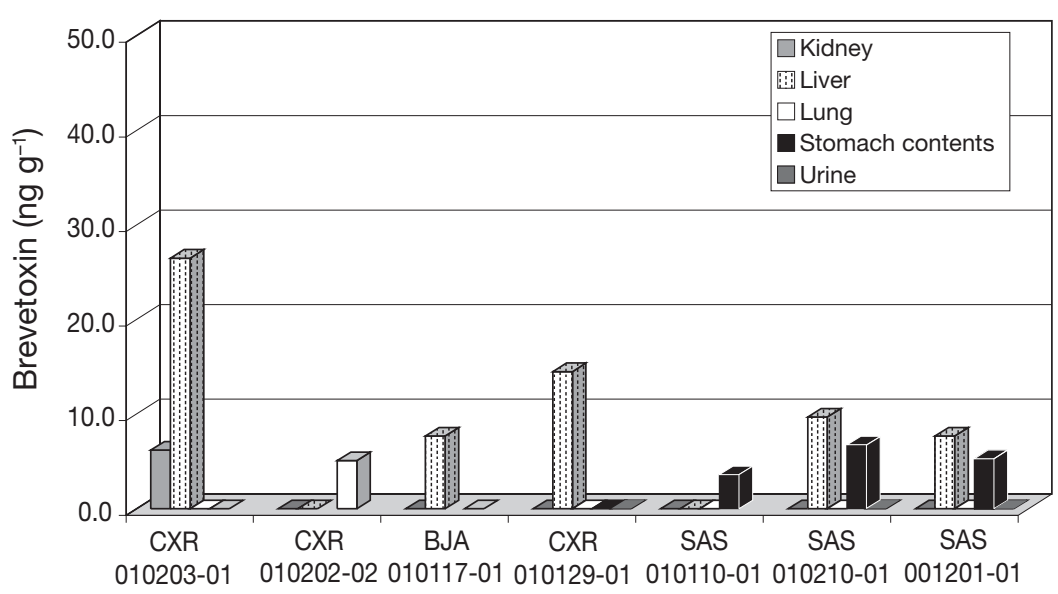

Fig. 11. Caretta caretta. Brevetoxins detected in tissues of 43 stranded turtles that were necropsied (Wolke et al. 1982). In that previous report, while multiple tissues contained up to 3 types of eggs, none were identified in the brain of 5 turtles that were examined. In a report involving a single green turtle in Australia, trematodes were found in meningeal vessels (Glazebrook \& Campbell 1981). While eggs were released into blood vessels supplying the brain, no inflammatory response was observed. The turtle was found in a debilitated, listless and weakened condition at sea, with severe muscle atrophy and orbital ocular recession, but no other clinical signs were reported. In a more recent study involving 96 green turtles, trematode eggs were seen in every organ examined, including the brain (Gordon et al. 1998). While light microscopy revealed trematodes in the meninges of 53 of $72(74 \%)$ green turtles, they were rarely associated with severe lesions. The meningeal lesions were considered severe in a single green turtle that had a hemorrhagic mass in the dorsal cranial cavity. Unfortunately the clinical appearance of this and other live turtles in the study were not correlated with lesions. Still, spirorchiid infections were considered the principal cause of mortality in 10 green turtles and contributed to the severe lesions seen in another 29 turtles (Gordon et al. 1998). In painted turtles Chrysemys picta picta experimentally infected with Spirorchis parvus, 1 turtle developed hemiplegia (Holliman et al. 1971). The left side of the 4 th ventricle of this turtle had adult flukes and was necrotic. in a turtle that is not feeding, we feel that the turtles had probably not been feeding for 1 or more weeks.

Light microscope evaluation of the brain, spinal cord and peripheral nerves of 18 affected LST revealed intralesional spirorchiid eggs in the brain of all 18, in the spinal cord of 15, and in the peripheral nerves of 8 . Burdens appeared to be higher in the affected LST than in a control group of LST that were necropsied either before the epizootic, or at the same time, north of the epizootic. Adult spirorchiids dissected from meningeal vessels of the brains of 2 affected LST and spinal cord of 1 affected LST were identified as Neospirorchis sp. (Price 1934, Manter \& Larson 1950). In LST, spirorchiidiasis was previously reported in 14
Table 5. Caretta caretta. Numbers of debilitated LST (n) with signs of neurological disease found during the 2 years (April 2001 to March 2003) following main period of epizootic. See Fig. 1 for county locations

\begin{tabular}{|lll|}
\hline Month & $\mathrm{n}$ & Counties \\
\hline June 2001 & 2 & Lee and Monroe \\
July 2001 & 3 & Monroe and Sarasota (2) \\
September 2001 & 1 & Sarasota \\
January 2002 & 3 & Miami-Dade and Monroe (2) \\
February 2002 & 2 & Monroe \\
March 2002 & 1 & Sarasota \\
April 2002 & 2 & Monroe and Pinellas \\
\hline
\end{tabular}


In the LST of the current epizootic, all 18 necropsied turtles had intralesional spirorchiid flukes or eggs in the CNS; eggs also were seen in peripheral nerves; 12 of the necropsied LST had moderate to large numbers of trematode eggs in the CNS. Based on the light microscope lesions that were associated with adult spirorchiids and their eggs in the brains of affected LST, their presence in the CNS could have contributed to the neurologic disease seen in these turtles.

As in other reports (Wolke et al. 1982, Gordon et al. 1998), in the LST in the present study, spirorchiid eggs were present in all visceral organs, often surrounded by granulomatous inflammation. Severe tracheitis and pneumonia in 1 of 18 necropsied LST in the current report was considered to be the cause of death. This turtle may have aspirated seawater or refluxed gastric contents secondary to the neurologic disease. While thrombosis was common in green turtles in Australia with spirorchiidiasis (Gordon et al. 1998), it was not a prominent feature of the disease in the LST of the current report.

Schistosomiasis remains one of the most prevalent parasitic infections in the world, affecting approximately 200 million people in 74 countries (WHO 1993), where they are responsible for considerable morbidity and mortality (Platt \& Brooks 1997). While schistosomes are dioecious, and all but 1 are venous specialists, spirorchiids are monecious and are vascular generalists, with a preference for the heart, great blood vessels and arteries. The 3 major human schistosomes, Schistosoma mansoni, S. haematobium and S. japonicum, can infect the CNS, and lesions seen in humans with neuroschistosomiasis (Pitella 1997) show many similarities to the lesions of neurospirorchiidiasis identified in the recent outbreak of LST. While considered rare, the human disease, in certain ways, may serve as a model for understanding the nature of the disease in sea turtles. In human schistosomiasis, CNS involvement is caused by ectopic deposition of eggs. Eggs and adult parasites are located in the venous system of humans, and thus must enter the CNS against the flow of blood. It is believed that these parasites and their eggs gain access to the spinal cord through avalvular anastomotic veins in the pelvic vertebral region or to the brain via pulmonary arteriovenous shunts (Scrimgeour \& Gajdusek 1985). Since adult spirorchiids are in the arterial system of turtles, both adult flukes and their eggs have easier access to the CNS, being able to travel directly to the brain through the cranial arterial system. This probably accounts for the large numbers of eggs and adult parasites seen in the brains of these turtles. While LST were infected with other genera of spirorochiids, only Neospirorchis sp. was identified in the brain. In a study in Australia, only N. schistosomatoides was identified in the brain of green turtles, even though Hapalotrema mehrai and $H$. postorchis were identified in the heart and great vessels (Gordon et al. 1998).

Myeloradiculopathy with paraplegia, lower limb weakness and pain has been reported in a number of human cases with spinal cord schistosomiasis (Scrimgeour \& Gajdusek 1985, Nobre et al. 2001). Acute tetraparesis (Junker et al. 2001) and a peripheral polyneuropathy (Mostafa et al. 1972) also have been reported in human schistosomiasis. In contrast to LST with neurospirorchiidiasis, clinically significant granulomas rarely develop in the brain of humans with neuroschistosomiasis (Scrimgeour \& Gajdusek 1985).

Neurologic examination of several affected LST supported a diagnosis of neuromuscular transmission blockade, and electron microscopy of brachial and sciatic nerves revealed demyelination. While inflammatory changes associated with adult spirorchiids and their eggs were seen in the CNS, we do not know if clinical signs and changes in peripheral nerves can be totally explained by the presence of these parasites and/or their eggs. There are no previous reports of a neurologic disease in LST caused by spirorchiid trematodes in the central nervous system.

Quadriplegia with loss of limb spinal reflexes, muscle tone and palpebral reflexes is most often due to a motor polyneuropathy or blockade of neuromuscular transmission involving spinal and cranial nerves (Chrisman et al. 2003). The loss of response to sensory stimuli in the affected LST could be associated with a concurrent sensory polyneuropathy affecting spinal and cranial nerves or an associated spinal cord and cerebral disorder. The severe depression of affected turtles could have resulted from their generalized cachexia or a concurrent cerebrum or brainstem lesion as a result of spirochiid infection.

On electrophysiological examination, the absence of positive sharp waves or fibrillation potentials with a relatively normal insertional activity excluded a peripheral axonopathy as a likely cause of the neurological disease in the LST. The absence of neurogenic atrophy in fresh, frozen muscle biopsy sections in any of the affected LST supported this assessment. The absence of observable, voluntary, motor unit action potentials in unanesthetized individuals and the lack of response to electrical stimulation of the sciatic nerve associated with the absence of insertional activity abnormalities indicated that affected turtles had either a primary demyelinating polyneuropathy sparing the axons or a neuromuscular transmission blockade (Chrisman et al. 2003). A demyelinating polyneuropathy could explain both the motor and sensory abnormalities detected in the neurologic examination.

Biospsy specimens of plastic embedded peripheral nerve from affected turtles were evaluated and con- 
firmed demyelination. Morphometric evaluation demonstrated that the density of myelinated nerve fibers was not significantly different from that of controls, consistent with an absence of axonal degeneration. Subperineural edema was evident in nerve biopsies from affected LST, suggesting a toxic, metabolic or inflammatory abnormality. A classical example of a toxic disorder causing a segmental demyelinating neuropathy and subperineural edema is lead intoxication. (Dyck et al. 1993). Lead levels, however, were evaluated in affected turtles and were found to be in normal ranges for all but 2 turtles. While a concurrent blockade of neuromuscular transmission cannot be ruled out, a junctionopathy alone would not result in demyelination of peripheral nerves. Toxic neuromuscular junction blockade has been seen with tick toxin, coral snake envenomation, botulism, curare, and other drugs in dogs and cats (Braund et al. 1996, Chrisman et al. 1996, 2003) and with toxic extracts and purified borbotoxins from the marine benthic dinoflagellate Prorocentrum borbonicum in mice (Ten-Hage et al. 2002).

Although spirochiid infection is common in sea turtles and may produce neurologic signs referable to lesions in the brain and spinal cord, a secondary polyneuropathy has not been previously observed or reported in sea turtles. As previously mentioned, acute tetraparesis (Junker et al. 2001) and a peripheral polyneuropathy (Mostafa et al. 1972) have been reported in human schistosomiasis. One hallmark of inflammatory demyelinating disorders in humans is the onset of a symmetric polyradiculoneuropathy, often following an upper respiratory infection or receipt of a foreign antigen (Dyck et al. 1993). Certainly the LST had evidence of inflammation although, if there was an aberrant immune response, the trigger was not clear. In dogs and cats, chronic inflammatory demyelinating polyneuropathies are thought to be associated with immune mediated disease (Dyck et al. 1993). However, the inflammatory response was directed toward the spirorchiid parasites rather then myelin. Another hallmark of inflammatory demyelinating disorders is edema, particularly around capillaries and beneath the perineurium. Subperineural edema was identified in 4 of 7 affected LST. While inflammation was not a feature of the LST nerve or muscle specimens, an inflammatory response may have had a focal or multifocal distribution and could have been missed, since all parts of the peripheral nerve including nerve roots and supporting structures were not evaluated.

Given that the preliminary neurological findings for affected LST in the Florida epizootic indicated a polyneuropathy, demyelination and/or neuromuscular junction blockade, a harmful algal bloom (HAB) biotoxin was considered in the differential diagnosis. While HAB in Florida are commonly caused by the red-tide organism Karenia brevis (Steidinger 1993), except for a report of a brown pelican mortality (T. Wilmers pers. comm.) that overlapped with the loggerhead sea turtle epizootic, there were no concurrent mortalities of other aquatic species that would typically occur after exposure to $K$. brevis brevetoxin (PbTx). The concentration of $K$. brevis in the Florida Keys area during months of the epizootic (F. Truby pers. comm. FWRI data posted at www.floridamarine.org) were considered below that seen in a typical red-tide event. Even though PbTx were found in some LST, the values were not considered to be particularly high. Given the almost yearly presence of Florida red tide along the west coast of Florida and the likely exposure of LST to $\mathrm{PbTx}$, there is no clear evidence to support PbTx as the single cause of the neurologic disease.

By light and electron microscopy, the major lesion seen in LST peripheral nerves was demyelination. While spirorchiid eggs were seen in peripheral nerves of 8 affected LST, there was no evidence to support a role in the demyelinating lesion. The most likely known microalgal toxin that might contribute to a demyelinating polyneuropathy in LST in Florida is CTX originating from the benthic dinoflagellate Gambierdiscus toxicus. In humans, CTX can cause a demyelinating polyneuropathy with intramyelinic edema or edema between myelin and axon with compression of the axon (Baden et al. 1994). However, the possible exposure of LST to CTX would not be a wellknown mode of toxin transfer through the food chain. G. toxicus is not a planktonic species and, therefore normally would not be consumed by filter-feeding shellfish that usually comprise the LST diet. If LST were to switch diets, or inadvertently consume large quantities of macroalgae or macrophytes, then there is a possibility that they could be exposed to CTX. While CTX was not detected in loggerhead tissue, it is possible that there are other derivatives of CTX that may not be identified using the preliminary screening methods adopted here.

A novel microalgal toxin yet to be identified may be involved in the neurological disease of LST. Possibly, the affected LST encountered an algal toxin in their prey. In adult and subadult LST, the most common dietary items are crustaceans and molluscs (Dodd 1988, Bjorndal 1997). The near lack of these items among the gastrointestinal tracts of the LST in the present investigation may indicate that these turtles had not been feeding normally prior to stranding. However, although cnidarians are more commonly known as a dietary item of smaller-sized LST, subadult and adult LST occasionally feed on cnidarians (Dodd 1988, Bjorndal 1997). One of the authors (A.M. Foley) has commonly observed sponges as dietary components of other LST from the Florida Keys. Cnidarians and 
poriferans were represented in gastrointestinal contents of the LST of the current report, with many containing nematocysts $(n=14)$, jelly-like flesh $(n=11)$, or spicules $(\mathrm{n}=8)$.

Heavy metal toxicosis also was considered as a possible cause of the LST neurologic disease, and assays for 15 metals were performed on liver and kidney samples of 9 affected turtles. Because of limited knowledge regarding normal ranges for this species, the results of this study were compared with findings of other studies of essential and nonessential elements in LST (Sakai et al. 1995, 2000, Gordon et al. 1998, Storelli et al. 1998, Torrent et al. 2004). Compared to these studies, tissues from the LST that died prior to the epizootic had noticeably higher values for only 1 element, $\mathrm{Pb}$, which is not surprising in a captive turtle. The liver also showed a slight elevation in $\mathrm{Hg}$ above the highest reported values, and the kidney a slight elevation in iron. All other values were either below detectable limits or within previously published ranges. Among the 9 affected turtles that were evaluated, 8 had at least 4 element values (most commonly $\mathrm{As}, \mathrm{Cr}, \mathrm{Hg}$ and $\mathrm{Se}$ ) in excess of the highest previously published concentrations, with 3 of them having moderately (up to 2-fold) to exceptionally high (up to 14 -fold, although 3to 5-fold is more typical) concentrations for up to 13 metals. Although potential toxicosis was not determinable for most elements, Cd was measured in 8 of the affected LST kidneys at levels greater than the $20 \mu \mathrm{g} \mathrm{g}^{-1}$ wet wt concentration associated with renal damage in marine mammals (Fujitse et al. 1988). While renal lesions (Table 1) were noted for a number of the affected LST, lesions consistent with Cd-induced nephrotoxicity (Goyer 1996) were not detected in the kidneys of the LST in this study. Also of concern were essential elements below the lowest published data range. In $2 \mathrm{LST}$, hepatic copper was below the published range; in 1 of these, the level was also low in the kidney. What constitutes a normal body burden of toxicants for a healthy LST is not yet known, nor do we know the necessary ranges of essential elements required for health. Unfortunately, these gaps in knowledge in combination with the variable elementsets and widely ranging levels found among the individual LST, raise more questions than answers. Still, while there is no indication that metal toxicosis was a primary cause of the epizootic incident, it cannot be ruled out as a secondary health issue.

When the LST with neurological disease were first identified, organophosphate toxicosis was suspected. Cholinesterase assays of plasma of affected turtles were not found to be significantly different from values of normal loggerheads, and this was ruled out as a cause of the clinical signs seen in the LST. Heavy metal toxicosis also was considered as a cause of the LST neurologic disease. While it is not known at what point LST experience overt toxic effects, the findings of the present study failed to clearly implicate any metal(s) as the cause of this epizootic.

In this report, the specific cause of the neurologic disease of LST was not satisfactorily identified. While inflammatory lesions and necrosis seen in the CNS of LST associated with spirorchiid trematode adults and their eggs could have contributed to clinical signs seen in the LST, there is no clear evidence to implicate these parasites as the only cause of this disease and, more specifically, the demyelinating lesion of peripheral nerves seen in affected LST. A neurotoxin-containing microalga was suspected, but our findings failed to implicate a toxin. Perhaps a novel algal toxin, yet to be identified, acted synergistically with the spirorchiid trematodes to cause the neurologic disease seen in these LST.

Acknowledegments. The authors thank Paul Klein, University of Florida, Gainesville, Florida, USA; Damien Shea, North Carolina State University, Raleigh, North Carolina,

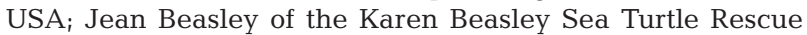
and Rehabilitaton Center, Topsail Island, North Carolina, USA; Fran Van Dolah and Tod Leighfield, Marine Biotoxins Laboratory, National Ocean Service, NOAA, Charleston, South Carolina, USA; Earnest Truby, FWRI, Florida Fish and Wildlife Conservation Commission, St. Petersburg, Florida, USA; $_{i}$ and the dedicated participants in the Florida Sea Turtle Stranding and Salvage Network, USA. The National Marine Fisheries Service, USA, the Caribbean Conservation Corporation, Gainesville, Florida, USA, and the Batchelor Foundation, College of Veterinary Medicine, University of Florida, Gainesville, Florida, USA, provided funding for this study. All heavy metal analyses were performed using the facilities at ABC Research Corporation, Gainesville, Florida, USA.

\section{LITERATURE CITED}

Baden DG, Fleming LA, Bean, JA (1994) Marine toxins. Handb Clin Neurol 21:141-175

Bjorndal KA (1997) Foraging ecology and nutrition of sea turtles. In: Lutz PL, Musick JA (eds) The biology of sea turtles. CRC Press, Boca Raton, FL, p 199-222

Bolten AB, Jacobson ER, Bjorndal KA (1992) Effects of anticoagulant and autoanalyzer on blood biochemical parameters of loggerhead sea turtles, Caretta caretta. Am J Vet Res 53:2224-2227

Bradley TA, Norton TM, Latimer KS (1998) Hemogram values, morphological characteristics of blood cells and morphometric study of loggerhead sea turtles, Caretta caretta, in the first year of life. J Herpetol Med Surg 8:8-16

Braund KG, Vallat JM, Steiss JE, Panangala VS, Zimmer PL (1996) Chronic inflammatory demyelinating polyneuropathy in dogs and cats. J Peripher Nerv Syst 1:149-155

Chrisman CL (1991) Special ancillary investigations. Problems in small animal neurology. Lea \& Febiger, Philadelphia, PA, p 89-100

Chrisman CL, Hopkins AL, Ford S, Meeks JC (1996) Suspected coral snake envenomation in four cats. J Am Anim Hosp Assoc 32:343-349 
Chrisman CL, Walsh M, Meeks JC, Zurawka H, LaRock R, Herbst L, Schumacher J (1997) Neurologic examination of sea turtles. J Am Vet Med Assoc 211:1043-1047

Chrisman C, Mariani C, Platt S, Clemmons C (2003) Acute quadriparesis, quadriplegia, hemiparesis and hemiplegia. In: Neurology for the small animal practitioner. Teton News Media, Jackson, WY, p 213-236

Dodd CK Jr (1988) Synopsis of biological data on the loggerhead sea turtle Caretta caretta (Linaeus, 1758). US Fish Wildl Serv Biol Rep:88:110

Dubowitz V (1985) Histological and histochemical stains and reactions. In: Dubowitz V (ed) Muscle biopsy. A practical approach. Bailliere Tindale, London, p 19-40

Dyck PJ, Giannini C, Lais A (1993) Pathologic alterations of nerves. Lead intoxication as a model of primary segmental demyelination. In: Dyck PJ, Thomas PK, Griffin JW, Low PA, Poduslo JF (eds) Peripheral neuropathy, 3rd edn. WB Saunders, Philadelphia, PA, p 514-595

Epperly SP, Braun J, Chester AJ, Cross FA, Merriner JV, Tester PA, Churchill JH (1996) Beach strandings as an indicator of at-sea mortality of sea turtles. Bull Mar Sci 59:289-297

Fujitse Y, Honda K, Tatsukawa R, Mishima S (1988) Tissue distribution of heavy metals in Dall's porpoise in the northwestern Pacific. Mar Pollut Bull 19:226-230

George RH (1997) Health problems and diseases of sea turtles. In: Lutz PL, Musick JA (eds) The biology of sea turtles. CRC Press, Boca Raton, FL, p 363-385

Glazebrook JS, Campbell RSF (1981) Pathological changes associated with cardiovascular trematodes (Digenea: Spirorchiidae) in a green sea turtle (Chelonia mydas (L). J Comp Pathol 91:361-368

Gordon AN, Kelly WR, Cribb TH (1998) Lesions caused by cardiovascular flukes (Digenea: Spirorchidae) in stranded green turtles (Chelonia mydas). Vet Pathol 35: 21-30

Goyer RA (1996) Toxic effects of metals. In: Klaassen CD (ed) Casarett and Doull's toxicology. The basic science of poisons, 5th edn. McGraw-Hill, New York, p 691-736

Gunter G, Williams RH, Davis CC, Smith FGW (1948) Catastrophic mass mortality of marine animals and coincident phytoplankton bloom on the west coast of Florida, November 1946 to August 1947. Ecol Monogr 18:309-324

Holliman RB, Fisher JE, Parker JC (1971) Studies on Spirorchis parvus (Stunkard, 1923) and its pathological effects on Chrysemys picta picta. J Parasitol 91:361-368

Junker J, Eckardt L, Husstedt I (2001) Cervical intramedullar schistosomiasis as a rare cause of acute tetraparesis. Clin Neurol Neurosurg 103:39-42

Landsberg JH (2002) The effects of harmful algal blooms on aquatic organisms. Rev Fish Sci 10:113-390

Lauckner G (1985) Diseases of reptilia. In: Kinne O (ed) Diseases of marine animals. Vol IV, Part 2. Biologische Anstalt Helgoland. Hamburg, p 553-626

Manter HW, Larson MI (1950) Two new blood flukes from a marine turtle, Caretta caretta. J Parasitol 36:595-599

Mizisin AP, Kalichman MW, Bache M, Dines KC, DiSefano PS (1998) NT-3 attenuates functional and structural disorders in sensory nerves of galactose-fed rats. J Neuropathol Exp Neurol 57:803-813

Mostafa M, Habib MA, Abdel-Moneim S, Abdel-Hamid T, Sherif M, Basmy K, Schoeb SM, Hassan AH (1972) Peripheral polyneuropathy in bilharziasis. J Egypt Med Assoc 55:44-59

Naar J, Bourdelais A, Tomas C, Kubanek J and 5 others (2002) A competitive ELISA to detect brevetoxins from Karenia brevis (formerly Gymnodinium breve) in seawater, shellfish, and mammalian body fluid. Environ Health Perspect 110:179-185
Nobre V, Silva LC, Ribas JG, Rayes A, Serufo JC, Lana-Peixoto MA, Marinho RF, Lambertucci JR (2001) Schistosomal myeloradiculopathy due to Schistosoma mansoni: report on 23 cases. Mem Inst Oswaldo Cruz 96(Suppl):137-141

Pitella JEH (1997) Neuroschistosomiasis. Brain Pathol 7: 649-662

Platt TR, Brooks DR (1997) Evolution of the schistosomes (Digenea: Schistosomatoidea): the origin of dioecy and colonization of the venous system. J Parasitol 83:1035-1044

Price EW (1934) New genera and species of blood flukes from a marine turtle, with a key to genera of the family Spirorchidae. J Wash Acad Sci 24:132-141

Raidal SR, Ohara M, Hobbs RO, Prince RIT (1998) Gram-negative bacterial infections and cardiovascular parasitism in green sea turtles (Chelonia mydas). Aust Vet J 76:415-417

Sakai H, Ichihashi H, Suganuma H, Tatsukawa R (1995) Heavy metal monitoring in sea turtles using eggs. Mar Pollut Bull 30:347-353

Sakai H, Saeki K, Ichihashi H, Suganuma H, Tanabe S, Tatsukawa R (2000) Species-specific distribution of heavy metals in tissues and organs of loggerhead turtle (Caretta caretta) and green turtle (Chelonia mydas) from Japanese coastal waters. Mar Pollut Bull 40:701-709

Scrimgeour EM, Gajdusek DC (1985) Involvement of the central nervous system in Schistosoma mansoni and S. haematobium infection. Brain 108:1023-1038

Shea D (1997) Analysis of brevetoxins by micellar electrokinetic capillary chromatography and laser induced fluorescence detection. Electrophoresis 18:277-283

Steidinger KA (1993) Some taxonomic and biological aspects of toxic dinoflagellates. In: Falconer IR (ed) Algal toxins in seafood and drinking water. Academic Press, London, p 1-28

Storelli, MM, Ceci E, Marcotrigiano GO (1998) Distribution of heavy metal residues in some tissues of Caretta caretta (Linnaeus) specimen beached along the Adriatic Sea (Italy). Bull Environ Contam Toxicol 60:546-552

Ten-Hage L, Robillot C, Turquet J, Le Gall F, Le Caer JP, Bultel V, Guyot M, Molgo J (2002) Effects of toxic extracts and purified borbotoxins from Prococentrum borbonicum (Dinophyceae) on vertebrate neuromuscular junctions. Toxicon 40:137-148

Torrent A, González-Díaz OM, Monagas P, Orós J (2004) Tissue distribution of metals in loggerhead turtles (Caretta caretta) stranded in the Canary Islands, Spain. Mar Pollut Bull 49:854-860

Tubaro A, Florio C, Luxich E, Sosa S, Della Loggia R, Yasumoto $\mathrm{T}$ (1996) A protein phosphatase 2A inhibition assay for a fast and sensitive assessment of okadaic acid contamination in mussels. Toxicon 34:743-752

Usleber E, Schneider E, Terplan G (1991) Direct enzyme immunoassay in microtitration plate and test strip format for the detection of saxitoxin in shellfish. Lett Appl Microbiol 13:275-277

USEPA (1996) Test methods for evaluating solid waste, physical/chemical methods (SW-846), 3rd edn, Final Update III, Chap 3. USEPA, Washington, DC

Van Dolah FM, Finley EL, Haynes BL, Doucette GJ, Moeller PD, Ramsdell JS (1994) Development of rapid and sensitive high throughput pharmacological assays for marine phycotoxins. Nat Toxins 2:189-196

WHO (World Health Organization) (1993) Public health impact of schistosomiasis. Bull WHO 71:623-657

Wolke RE, Brooks DR, George A (1982) Spirorchidiasis in loggerhead sea turtles (Caretta caretta): pathology. J Wildl Dis 18:175-185

Zar JH (1984) Biostatistical analysis, 2nd edn. Prentice-Hall, Englewood Cliffs, NJ 